\title{
Revision of the enigmatic insect family Anthracoptilidae enlightens the evolution of Palaeozoic stem-dictyopterans
}

\author{
Zhaoying Guan, Jakub Prokop, Patrick Roques, Jean Lapeyrie, and André Nel \\ Acta Palaeontologica Polonica 61 (1), 2016: 71-87 doi:http://dx.doi.org/10.4202/app.00051.2014
}

The position of the Palaeozoic Anthracoptilidae has been a major problem of insect systematics for over a century. The previous hypotheses suggested affinities of Anthracoptilidae with the Palaeodictyopteroida, Protorthoptera, Hypoperlida, stem-Mantodea, Paraneoptera, Holometabola, or Eoblattida. Herein we put forward a new hypothesis based mainly on a comprehensive re-evaluation of the wing venation characters and re-examination of the type material of Anthracoptilus perrieri and Mesoptilus dolloi. The Anthracoptilidae are considered as belonging to the paoliid lineage, sister group of the Dictyoptera. In particular this result refutes the presence of Mantodea in the Paleozoic fossil record. The two families Strephocladidae and Strephoneuridae, are considered as junior synonyms of the Anthracoptilidae, while the previous synonymy of the Anthracoptilidae with the Ischnoneuridae is rejected. We consider the Permarrhaphidae, previously considered as synonym of the Anthracoptilidae, (and Permarrhaphus ) as Insecta incertae sedis. The following new taxa are proposed: Mesoptilus carpenteri sp. nov. from the early Permian of Wellington Formation in Oklahoma (USA) which extends the range and distribution of the genus; Pseudomesoptilus gen. nov. is designated to include Mesoptilus sellardsi; Strephocladus permianus sp. nov. from the middle Permian of South of France; Westphaloptilus gallicus gen. et sp. nov. from the Bashkirian of the North of France.

Key words: Insecta, Neoptera, Paoliida, systematics, Carboniferous, Permian, France, USA.

Zhaoying Guan [guanzy300@aliyun.com], Institute of Hydrobiology, Jinan University, 510632 Guanzhou City, China. Jakub Prokop [jprokop@natur.cuni.cz ] (corresponding author), Charles University in Prague, Faculty of Science, Department of Zoology, Viničná 7, CZ-128 44, Praha 2, Czech Republic. Jean Lapeyrie [jean.lapeyrie@ orange.fr], Corniche de Fontbonne, F-34700, Lodève, France. Patrick Roques [patrick.roques93@wanadoo.fr] and André Nel [anel@mnhn.fr] (corresponding author), CNRS UMR 7205, CP 50, Entomologie, Muséum National d'Histoire Naturelle, 45 rue Buffon, F-75005 Paris, France. 
This is an open-access article distributed under the terms of the Creative Commons

Attribution License (for details please see creativecommons.org), which permits unrestricted use, distribution, and reproduction in any medium, provided the original author and source are credited.

FaF Full text $(1,660.9 \mathrm{kB})$ 